\title{
Evidence for the presence in Burkholderia pseudomallei of a type III secretion system- associated gene cluster
}

\author{
C. WINSTANLEY, B. A. HALES and C. A. HART* \\ Department of Biomedical Sciences, University of Bradford, Bradford, West Yorkshire BD7 1DP and \\ * Department of Medical Microbiology and Genito-Urinary Medicine, University of Liverpool, PO Box 147, \\ Liverpool $L 69$ 3BX
}

\begin{abstract}
Burkholderia pseudomallei, the causative agent of melioidosis, contains a cluster of putative genes homologous to those encoding HpaP, HrcQ, HrcR, HrcS and HrpV in the plant pathogen Ralstonia solanacearum. In $R$. solanacearum, these genes form part of a type III secretion-associated pathogenicity island. The order of the genes in $B$. pseudomallei is directly equivalent to that found in $R$. solanacearum. The $B$. pseudomallei proteins share 49.5\% (HpaP), 52.6\% (HrcQ), 80.0\% (HrcR), 72.1\% (HrcS) and 46.7\% (HrpV) similarity, respectively, with their equivalent $R$. solanacearum proteins. The presence of type III secretion-associated genes in $B$. pseudomallei pathogens suggests a possible role for type III secretion systems in the pathogenicity of this organism.
\end{abstract}

\section{Introduction}

Burkholderia (formerly Pseudomonas) pseudomallei is the causative agent of melioidosis, an often fatal infection endemic in areas of South East Asia and Australia, where it is a major cause of communityacquired septicaemia [1]. Although some potential virulence factors have been identified, overall knowledge of the pathogenicity of $B$. pseudomallei is limited. However, a number of its secreted products, including protease, haemolysin, lipase and lecithinase $[2,3]$ have been linked to virulence.

Pathogenicity islands (PIs), virulence genes found in large contiguous groups, have been identified in several bacterial pathogens $[4,5]$. In some gramnegative bacteria, PIs have been associated with type III secretion systems $[4,6,7]$, which are made up of a number of proteins homologous with components of flagellum-specific export apparatus, and are involved in delivering virulence factors directly to host cells $[4,6]$. In contrast to type I and type II secretion

Received 6 Oct. 1998; accepted 21 Oct. 1998.

Corresponding author: Dr C. Winstanley. Present address: Department of Medical Microbiology and Gento-Urinary Medicine, University of Liverpool, PO Box 147, Liverpool L69 3BX. (e-mail: C.Winstanley@liverpool.ac.uk). systems $[8,9]$, type III secretion is triggered by a pathogen coming into close contact with host cells $[4,6,10]$.

Type III secretion system-associated PIs have also been characterised in a number of plant pathogens $[6,11,12]$, including Ralstonia (formerly Burkholderia) solanacearum, the causative agent of bacterial wilt in various crops and plants [13]. In this organism, five transcription units of the $h r p$ gene cluster (involved in development of the hypersensitive response, HR) are required for the secretion of the HR-inducing protein, PopA1. The nucleotide sequence for the entire region $(18300 \mathrm{bp}$ ) of the $R$. solanacearum strain GMI1000 $h r p$ gene cluster implicated in the secretion of PopA1 has been reported, including all five transcription units, encoding a total of $20 \mathrm{Hrp}$ proteins [13].

This study reports the use of a $R$. solanacearum hrp gene probe to identify, clone and sequence $B$. pseudomallei genomic DNA with homology to type III secretion-associated genes.

\section{Materials and methods}

Bacterial strains and plasmids

B. pseudomallei E503 was isolated from a patient with melioidosis in Malaysia [14]. R. solanacearum GMI1000 and cosmid $\mathrm{pVir} 2$, which carries most of the hrp gene 
cluster of strain GMI1000 [15], were provided by Dr M. Arlat and P. Barberis (Laboratoire de Biologie Moléculaire des Relations Plantes-Microorganismes, INRACNRS, BP27, 31326 Castanet Tolosan Cedex, France).

\section{Construction of gene libraries}

Genomic DNA, extracted from B. pseudomallei E503 as described previously [16], was employed to construct gene libraries with the SuperCos 1 Cosmid Vector Kit (Stratagene) and the conditions recommended by the supplier.

\section{Identification of cosmid clones homologous to hrp probes}

Oligonucleotide primers, obtained from Genosys Biotechnologies (Europe), Cambridge, for PCR amplification were designed with the sequence information available for the $h r p$ locus of $R$. solanacearum [13]. A combination of the primers BS7 (5'-TGCTCAGCGATAGGTGTTGACCAG-3') and BS8 (5'-ATTGCATCCATCGGCAAGCACCA-3') was employed to generate an amplified product of $1010 \mathrm{bp}$ (location 3106-4116 GenBank Accession no. z14056) encompassing the whole of $h r c R(h r p T)$ and part of $h r c Q$ (hrpQ). pVir2 cosmid DNA was isolated with a Midipreparation kit (Qiagen); $1 \mu \mathrm{l}$ of various dilutions of pVir2 DNA was used directly in $25-\mu 1$ volumes containing 2 units of Dynazyme (Flowgen), $200 \mathrm{nM}$ of each primer (BS7 and BS8), $1 \times$ Dynazyme buffer and $100 \mu \mathrm{M}$ nucleotides (dATP, dCTP, dGTP, dTTP). Amplifications were carried out in a MiniCycler (Genetic Research Instrumentation) for 30 cycles consisting of $95^{\circ} \mathrm{C}(1 \mathrm{~min}), 60^{\circ} \mathrm{C}(1 \mathrm{~min})$ and $72^{\circ} \mathrm{C}(2 \mathrm{~min})$ with an additional extension time at $72^{\circ} \mathrm{C}(10$-min) after completion of the 30 cycles. At the end of the amplification, 10- $\mu 1$ samples were subjected to electrophoresis on a standard agarose $1.0 \% \mathrm{w} / \mathrm{v}$ gel to confirm the presence of an amplified product. The 1010-bp amplified product was labelled with digoxigenin-11-2'dUTP (DIG; Boehringer Mannheim) by repeating the PCR reaction with $60 \mu \mathrm{M}$ DIG in a total reaction volume of $50 \mu \mathrm{l}$. The labelled product was used as a probe to identify homologous gene-containing clones from a B. pseudomallei E503 gene library. The presence of DIG on colony blots was detected by anti-DIG-AP Fab fragments and the chemiluminescent substrate CDP-Star (Boehringer Mannheim) in the procedure recommended by the supplier.

\section{Subcloning of hybridising genomic regions}

Cosmid DNA was isolated with a Midi-preparation kit (Qiagen) and subjected to restriction endonuclease (Helena Biosciences) digestion and agarose $(0.7 \%$ $\mathrm{w} / \mathrm{v})$ gel electrophoresis by standard procedures. Smaller hybridising fragments, identified by Southern blot analysis of digested cosmid clones, were subcloned into the plasmid vector pUC19 (Helena Biosciences).

\section{Nucleotide sequencing and computer analyses}

DNA was purified from putative clones with a QIAprep Spin Miniprep Kit (Qiagen). Both strands of the cloned insert DNA were sequenced by primer walking at the University of Liverpool DNA Sequencing Service with vector and internal oligonucleotide primers.

Nucleotide sequence alignments, $\mathrm{G}+\mathrm{C}$ mol\% values, determination of amino acid composition, predicted protein mass and alignments of predicted proteins with other related proteins (retrieved from EMBL, GenBank, PIR or SwissProt [17]) were performed with GAP, PILEUP, COMPOSITION, PEPTIDESORT and FASTA programs from the GCG sequence analysis software package (Genetics Computer Group, University of Wisconsin). Hydrophobicity profiles and predictions of membrane-spanning regions were obtained with the PEPTIDESTRUCTURE and PEPPLOT programs, employing the hydropathy measure of Kyte and Doolittle [18] and the measure of helical hydrophobic moment [19].

\section{Accession number}

The 4490-bp B. pseudomallei nucleotide sequence reported in this study has been lodged under the GenBank accession number AFO42488.

\section{Results}

\section{Identification of cosmid clones containing putative type III secretion genes}

With a DIG-labelled PCR-amplified product as a probe, it was possible to identify $B$. pseudomallei E503 cosmid clones showing strong homology to the region of the $R$. solanacearum GMI1000 genome encoding HrcR and part of HrcQ. To locate the hybridising region more accurately, DNA was isolated from one representative hybridising cosmid clone, digested with several restriction endonucleases (including SalI and Pst I) and probed by Southern blot hybridisation.

\section{Nucleic acid and predicted protein sequence comparisons}

Hybridising fragments of $B$. pseudomallei E503 genomic DNA of $2.6 \mathrm{~kb}$ (generated with SalI) and $c .3 .0 \mathrm{~kb}$ (generated with PstI ) were subcloned into pUC19 and subjected to DNA sequencing (Fig. 1). The overlapping fragments enabled a nucleotide sequence of $4490 \mathrm{bp}$ to be determined. A database comparison indicated that by far the best homology for this sequence was to regions of the $R$. solanacearum type III secretion-associated PI [13] (GenBank Accession no. z14056). Within the $B$. pseudomallei nucleotide sequence, five complete open reading frames (ORFs) were identified. Predicted protein sequences, obtained for each of the five ORFs, suggested the presence of putative genes homologous to those encoding HpaP, HrcQ (HrpQ), HrcR (HrpT), HrcS (HrpU) and $\mathrm{HrpV}$ genes of the $R$. solanacearum type III 


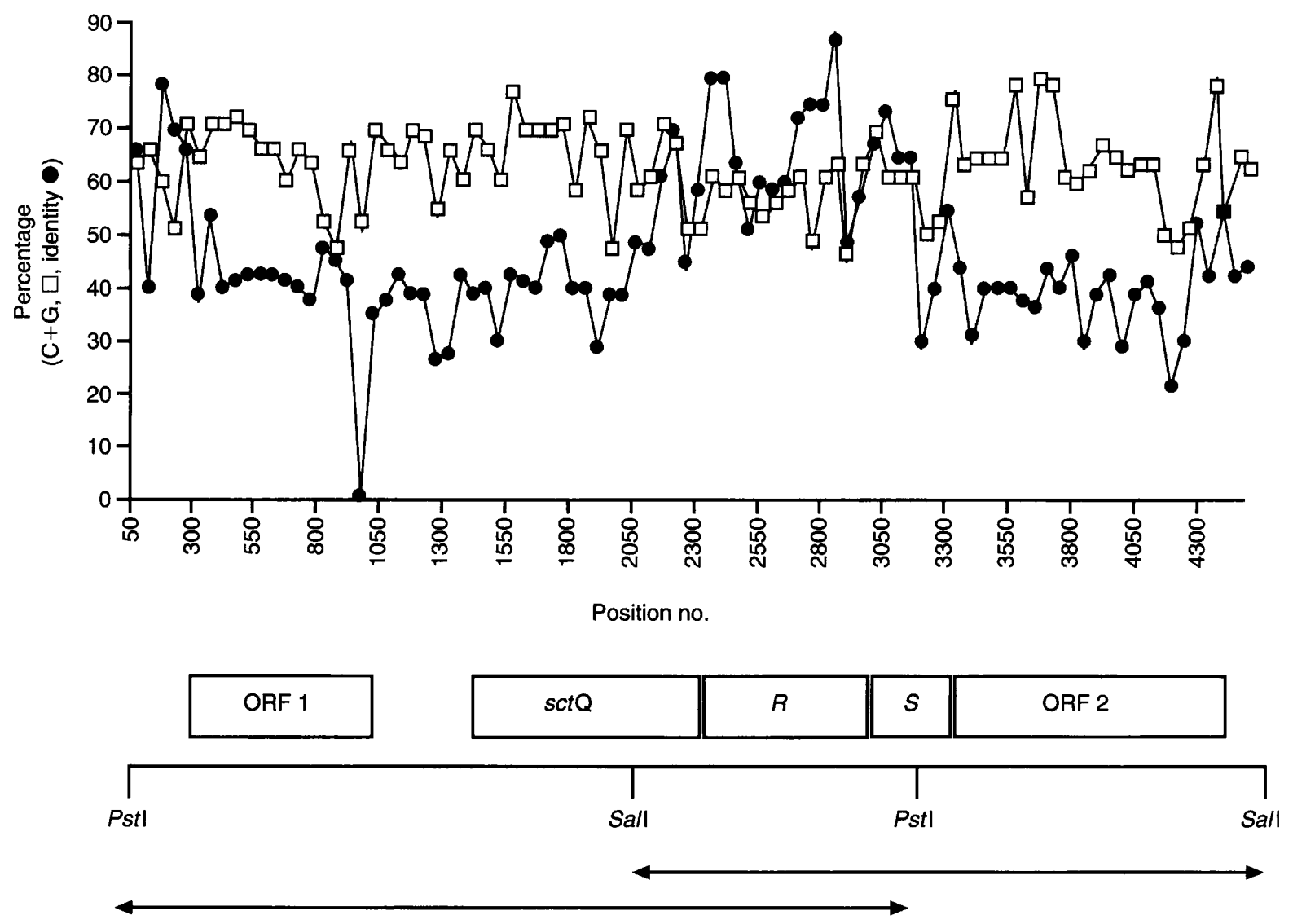

Fig. 1. Map of the B. pseudomallei gene cluster. The relative positions of the putative genes are shown. Arrowed lines indicate the subcloned regions used for sequencing (a SalI fragment and a PstI fragment). The upper figure shows a graph of $\mathrm{G}+\mathrm{C}$ mol\% content and percent identity with the equivalent $R$. solanacearum gene cluster, against position. The $G+C(\square)$ and identity $(\odot)$ values were obtained by analysis of 50 -bp segments of the B. pseudomallei gene cluster nucleotide sequence.

secretion system, and that the genes were clustered in the same order [13]. The Hrc designations are as suggested by Alfano and Collmer [12]. Previous designations, as reported for $R$. solanacearum by Van Gijsegem et al. [13], are indicated in brackets. Under the unified nomenclature suggested by Hueck [6], three of the $B$. pseudomallei predicted proteins have been designated SctQ (HrcQ homologue), SctR (HrcR homologue) and SctS (HrcS homologue). Because they lack homologues in the majority of type III secretion systems reported to date, the $\mathrm{HpaP}$ (ORF1) and $\mathrm{HrpV}$ (ORF2) homologues are not included in the unified nomenclature. SctR and SctS had the highest homologies with previously reported proteins. SctR/SctS homologues are transmembrane protein components of type III secretion systems, including YscR/YscS of Yersinia pestis, Spa24/Spa9 of Shigella flexneri and SpaP/SpaQ of Salmonella enterica serotype Typhimurium, all from genes important in animal pathogenicity [4]. Alignments of SctR/SctS with equivalent proteins from a number of type III secretion systems are shown in Fig. 2. Hydrophobicity profiles of $B$. pseudomallei SctR/SctS and $R$. solanacearum $\mathrm{HrcR} / \mathrm{HrcS}$ were used to identify a number of transmembrane-predicted regions, which were in broad agreement with the previous report of Van Gijsegem et al. [13]. In the SctR homologues, all but one of the four predicted transmembrane regions were in highly conserved regions of the protein (Fig. 2a, Table 1). The SctS homologues contained two predicted transmembrane regions separated by a short hydrophilic region (Fig. 2b, Table 1).

The predicted protein sequences for the other three putative $B$. pseudomallei proteins were aligned with their $R$. solanacearum homologues (Fig. 3). Predicted features and sequence similarity/identity measurements for all the proteins are presented in Table 1 . Comparison of the $B$. pseudomallei $\mathrm{HpaP}$ homologue sequence against protein databases confirmed that by far the best homology was with $R$. solanacearum HpaP. The HpaP protein of $R$. solanacearum is unusually rich in proline $(15 \%$ of total amino acid residues), a feature that may be important in tertiary structure [20]. The B. pseudomallei HpaP homologue contained 22 proline residues $(9.7 \%)$, making it the third most frequent residue. SctQ homologues exhibit homology only at the C-terminal region [13], making comparisons of the whole protein difficult. Alignment of the last $80 \mathrm{C}$-terminal residues of $B$. pseudomallei SctQ and $R$. solanacearum HrcQ reveals $72.5 \%$ similarity and $42.5 \%$ identity (Fig. 3 ). The putative $\mathrm{HrpV}$ homologue is the least conserved of the $B$. pseudomallei predicted protein sequences, but its hydrophobicity profile, $\mathrm{pI}$ and $\mathrm{M}_{\mathrm{r}}$ are similar to $R$. 
(a)

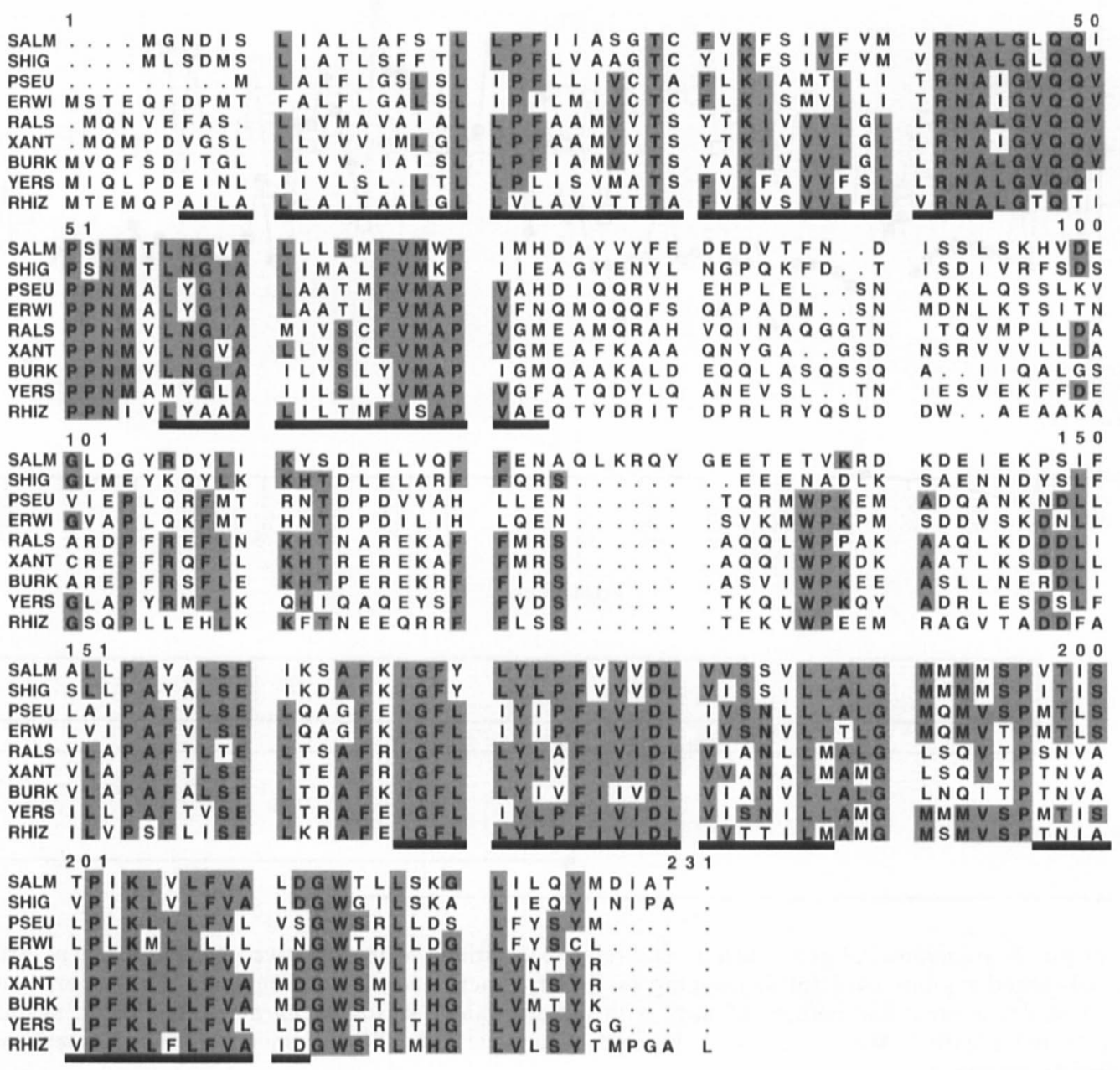

(b)
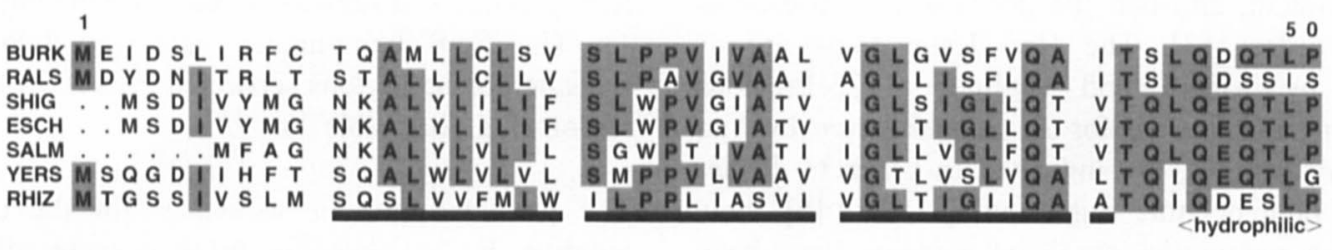

51
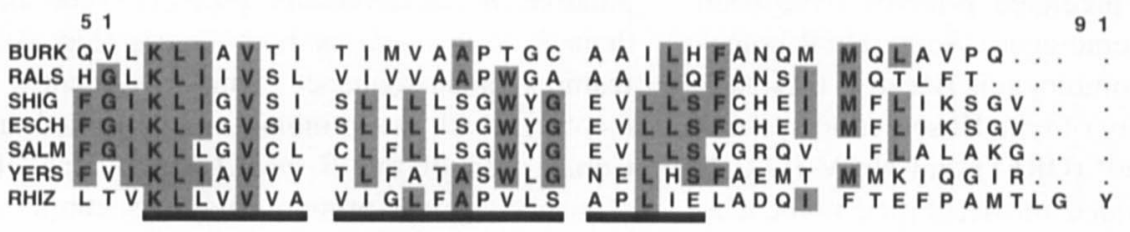

Fig. 2. Comparison of putative B. pseudomallei SctR and SctS protein sequences with homologues from other organisms encoding type III secretion systems. Alignment of $B$. pseudomallei (BURK) sequences with related proteins from Salmonella (SALM), Shigella (SHIG), Pseudomonas (PSEU), Erwinia (ERWI), Ralstonia (RALS), Xanthomonas (XANT), Yersinia (YERS), Rhizobium (RHIZ) and Escherichia (ESCH) are shown for SctR (a) and SctS (b). Residues conserved in $>50 \%$ of the sequences used are shaded. Thick black lines indicate the location of hydrophobic regions.

solanacearum $\mathrm{HrpV}$ (Table 1), indicating the possibility of similar roles in both organisms. Although a complete ORF is not yet available, there is evidence in $B$. pseudomallei for nucleotide sequence homology with the $R$. solanacearum gene encoding $\mathrm{HrcV}$ (HrpO) $(65.8 \%$ identity in $260 \mathrm{bp})$ upstream of the $h p a P-h r c Q-h r c R-h r c S-h r p V$ region. When translated, a downstream incomplete ORF yields a peptide sequence of 93 residues with $56.7 \%$ similarity (GAP alignment) to the $97 \mathrm{~N}$-terminal residues of $R$. solanacearum HrpW.

\section{Discussion}

PIs are thought to offer bacteria the possibility of acquiring, in one genetic event, a virulence trait, such as secretion of specific toxins in response to host cell 
Table 1. Predicted properties of putative type III secretion-associated B. pseudomallei proteins

\begin{tabular}{|c|c|c|c|c|c|}
\hline $\begin{array}{l}\text { Coding } \\
\text { gene* }^{*}\end{array}$ & $\begin{array}{l}\text { Similarity/ } \\
\text { identity }(\%)^{\dagger}\end{array}$ & Length $^{\ddagger}$ & $\mathrm{pI}^{\ddagger}$ & $\mathrm{M}_{\mathrm{r}}^{\ddagger}$ & Features \\
\hline $\begin{array}{l}\text { ORF1 } \\
(\text { hpaP })\end{array}$ & $49.5 / 28.4$ & $\begin{array}{c}227 \\
(197)\end{array}$ & $\begin{array}{l}6.8 \\
(6.1)\end{array}$ & $\begin{array}{l}24828 \\
(21959)\end{array}$ & No strongly hydrophobic domains \\
\hline $\begin{array}{l}\operatorname{sct} Q \\
(\operatorname{hrc} Q)\end{array}$ & $52.6 / 27.6$ & $\begin{array}{l}311 \\
(254)\end{array}$ & $\begin{array}{l}5.6 \\
(6.8)\end{array}$ & $\begin{array}{l}33358 \\
(37809)\end{array}$ & $\begin{array}{l}\text { Aligns well only at the C-terminus; no strongly } \\
\text { hydrophobic domains }\end{array}$ \\
\hline $\begin{array}{l}s c t R \\
(h r c R)\end{array}$ & $80.0 / 66.0$ & $\begin{array}{c}216 \\
(217)\end{array}$ & $\begin{array}{c}7.7 \\
(9.3)\end{array}$ & $\begin{array}{c}23662 \\
(23739)\end{array}$ & $\begin{array}{l}\text { A number of hydrophobic regions (resembling the } \\
\text { equivalent } R . \text { solanacearum protein) }\end{array}$ \\
\hline $\begin{array}{l}s c t S \\
(h r c S)\end{array}$ & $72.1 / 55.8$ & $\begin{array}{c}87 \\
(86)\end{array}$ & $\begin{array}{c}5.5 \\
(5.1)\end{array}$ & $\begin{array}{c}9193 \\
(8958)\end{array}$ & $\begin{array}{l}\text { Two hydrophobic domains separated by a short } \\
\text { hydrophilic region (as for the equivalent } R \text {. } \\
\text { solanacearum protein) }\end{array}$ \\
\hline $\begin{array}{l}\text { ORF2 } \\
(h r p V)\end{array}$ & $46.7 / 24.9$ & $\begin{array}{c}317 \\
(333)\end{array}$ & $\begin{array}{c}10.3 \\
(10.5)\end{array}$ & $\begin{array}{c}34417 \\
(36351)\end{array}$ & No strongly hydrophobic domains \\
\hline
\end{tabular}

*Equivalent $R$. solanacearum genes are indicated in brackets.

${ }^{\dagger}$ Similarity and identity between $B$. pseudomallei and $R$. solanacearum homologues are indicated.

${ }^{\ddagger}$ Values for $R$. solanacearum homologues are shown in brackets.

proximity. The presence in $B$. pseudomallei of adjacent putative SctR and SctS coding regions, exhibiting high homology to equivalent $R$. solanacearum proteins, and three other ORFs with predicted proteins exhibiting homology to equivalent $R$. solanacearum type III secretion components, suggests a cluster of related genes similar to those located in the PI of $R$. solanacearum. The gene organisation for B. pseudomallei and $R$. solanacearum is identical, indicating that similar PIs may reside in these two organisms, despite the fact that one is pathogenic for man and the other for plants. The order of the sctQRS gene cluster is also conserved in $Y$. pestis [21], Sh. flexneri [22], S. enterica [23] and the plant pathogens Erwinia amylovora, Pseudomonas syringae and Xanthomonas campestris [12]. Both SctR and SctS homologues contain predicted membrane-spanning regions and are thought to reside in the inner membrane [6].

Proteins homologous to $R$. solanacearum HpaP and $\mathrm{HrpV}$ have not been reported previously in animal pathogens, although an $\mathrm{HpaP}$ homologue has been reported in $X$. campestris, a plant pathogen that has considerable similarities to $R$. solanacearum in the organisation of its type III secretion system genes [24]. The actual sequence of this homologue is not available for analysis. Although the homology between $\mathrm{HpaP}$ and its putative $B$. pseudomallei homologue is lower than that observed for SctR and SctS, the similarity in properties suggests that the role of the putative protein may be similar in both organisms. As yet, no function has been ascribed to this protein, which has no hydrophobic domains [20]. The $R$. solanacearum $\mathrm{HrpV}$ protein, which exhibits the lowest homology with its proposed $B$. pseudomallei equivalent, has also not been ascribed a function. Although the role of $R$. solanacearum $\mathrm{HpaP}$ and $\mathrm{HrpV}$ and their putative $B$. pseudomallei equivalents is not known, the observed divergence between the two organisms suggests that these two proteins are not confined by the same structural constraints as SctQ, SctR or SctS. It may be that $\mathrm{HpaP}$ and $\mathrm{HrpV}$ homologues have a role specific in adaptation to a host or secretion of different virulence factors. Sequence similarities for
SctQ homologues are restricted to their $80 \mathrm{C}$-terminal amino acids [6]. It has been suggested that this protein may provide a link between common and speciesspecific components of type III secretion systems [6]. The presence, at either end of the gene cluster, of nucleotide sequences homologous to $R$. solanacearum $h r c V$ and $h r p W$, strongly suggests that a gene order is maintained between $B$. pseudomallei and $R$. solanacearum beyond the five putative genes reported in this paper. More sequencing will be required to determine fully the extent of the $B$, pseudomallei putative PI and its relationship to other type III secretion systemassociated PIs.

It has been observed that whilst the majority of genes in individual type III secretion systems encode proteins with homologues in other systems, each respective system may contain genes not widely observed in other systems and often unique to itself [6]. In the type III secretion systems of $R$. solanacearum, X. campestris and $B$. pseudomallei, there is good conservation of the gene orders. This supports the notion of an ancestral type III secretion system acquired by one organism from another. The relatively high similarities across species barriers amongst the proteins supports this idea. However, neither the homology nor the $\mathrm{G}+\mathrm{Cmol} \%$ content is uniform throughout the $B$. pseudomallei gene cluster. The overall $\mathrm{G}+\mathrm{C}$ content for the 4490-bp sequence $(63.1 \mathrm{~mol} \%)$ is lower than the value obtained for the $R$. solanacearum hrp locus $(18300 \mathrm{bp}$; $69 \mathrm{~mol} \%$ ), but is consistent with values reported for Burkholderia coding regions - including the $\mathrm{AlC}$ gene of $B$. pseudomallei $(65 \mathrm{~mol} \%)$ [14], the fliC gene (64 mol\%) [25] or cable pili pilin gene $(c b l A)$ of $B$. cepacia $(62 \mathrm{~mol} \%)$ [26], albeit lower than the value reported for B. cepacia genomic DNA (67 mol\%) [27]. However, there is fluctuation within the 4490-bp sequence. For example, the $\mathrm{G}+\mathrm{C}$ value for the putative $s r c R$ coding region is $57 \mathrm{~mol} \%$. A lower than average $\mathrm{G}+\mathrm{C}$ content is also found in the $h r c R$ gene of $R$. solanacearum (64.4\%). Fig. 1 demonstrates the variation in $\mathrm{G}+\mathrm{C}$ content, and the correlation with conservation between $B$. pseudomallei and $R$. solanacearum throughout the gene cluster. In many organ- 
(a)

1 .TRIGELELPVQFEIDTVSLPIDQLSALE'PGYVIELPVAVTDARLRLVVH 49 $\ldots:::||:||::|: \ldots:::|: .:||.|:| \ldots|:|||.|:| \ldots:|||$.

1 GVPLEQLEVPVHLELAVMGMPLAELAALQPQHVLTLPVKIRDVSVRLVCH 50

50 GQTVGYGELVAVGEHLGVRIIRMAHRHGTVQ 80

||$|:| .|:||||||:| \mid:$..$:::$ : :

51 GQYLGHGQLVAVGEQLGLQIASIGKHHAER. 80

(b)

1 MTTVAHIGSRPLRIIPGSTPAAPDETRQRRFDYASLVRAQQARRGPVTRSA 50

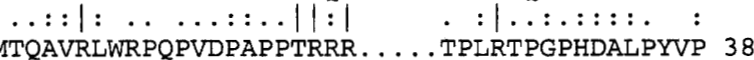

$1 \ldots \ldots$ MTQAVRLWREQPVDPAPPTRRR . . . . TPLRTPGPHDALPYVP 38

51 PPPPPGSERSWALAPSSGŚCDETAPAAGNTTRAPSTPFDETLDGNPVIAP 100

39 PPRPEPPE.......... PVEDDFPEPRQDTPASDPPPEARTDA....SP 74

101 PTCPIDAHESFGRVRHAIAPVVSVIVERQSंHFTRIVGM. . LAREIGAFC 147 | : : |:.. : $\quad .|::|:.|\quad| .:$. . . | || : :. . |

75 PQPAADPDASL..... HTAAIASRLVRTCSEIGAGETMTEHLARLLSQFC 119

148 SDGAIVCAGNं. WEAQLTLDPELLPRTTLHVALSRFIIRIRFDVPDGETR்D 196 $\ldots||::|:||| .|||.:||||:||. .::||: \ldots$.$| .$

120 ASQAIRSGGECWEISLDLDPKILPETRLTLRLSPHTLSLRFEAGHPRSRH 169

197 LLLTHRSLLËRELDEVMRCẂGEARDIQLSV̈W* 228

||$\cdot|\cdot|$. : : : : : : $|::| .:||$

170 LLSEHGDTLRQRIHALLR. . QQVDVELELW* 198

(c)

$1 \ldots \ldots \ldots \ldots \ldots$
$\|$ MPARKSSEEACVNRSFRSSNHLSSPAQLQQSADAQ 35

1 MTRITGPSSAIYTLPDPATTPAQPAAAT. . . PNTHRRRPRQLHEREIEH 46

36 QRAADRQAARNSALTAALYRGTTNFTYSKDPAPRGRLPSVSKTNALARKR 85 $:: \ldots \mid:: . \ldots\|\quad\|$. $.|| \mid::$

47 EHEQDHELQYQEQLT...............RRKQLAK...LAKRI 74

86 KITSRLRRNAAGNGDGDDVDGAL ............ VPHFEAEPGGDRD 121

$: .:|||| \ldots:|: \ldots|: .: \quad \mid:$ : . . $:$.

75 RRPGLKRRNAANAADEPTTDSDFEELLMIMEEHARLSKPLLVGPSKQGNP 124

122 RGGRGGREQPRDDPMDIETCRRLPRMOAAESRAAAAPRGRFDAVADLHHA 171 $::|\ldots||\ldots: \ldots|: \ldots:: \mid$. . |. ||.|::: .| |: .|

125 HDGQQGR. RGNNPQSDLAGRHAMLRRYLLEAEAAEAAKAEEKASAQASSA 173

172 PGQEGERADAIARAWESEMFGLRVFSPNAPRTAEILELSLDFLLIQRRIG 221

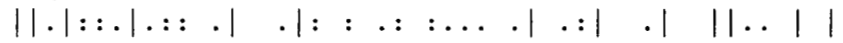

174 PGKEAGSAAPVLPAQRKEL. AAQLTGTAEIPTYKMLLAELCALLYAVRAG 222

222 PIPVSTLAR . . . ... LLRESP. . .APTPVACGRDRLPGETAPDDRR . . . . 257

$$
\text { . || }::|| \text { || .: ..: | .: ..: . : : : }
$$

223 HSMPLRLALNLSRAFIKASPLAGAPETLHAVKKDLVASVPPAEHKARSER 272

258 . RFNLLFPLLWLQAGMPRTAIRLDCAIAKLLAIRNALPDNPLATDDAQA 305

$|:||:||::||::||| \ldots .: .|:|:$. : ..:.:.:.:|

273 EEAFHLLLPLMLISASLPRTSTMKSEGYARSGALARRWEAEVWSHQAGVA 322

306 EPTPAPHASSSE* 318

$:|\cdot| \cdot \mid$.

323 GMTVRPINVSA*. 334

Fig. 3. Comparison of putative $B$. pseudomallei proteins with $R$. solanacearum HrcQ, HpaP and HrpV. GAP alignments are shown for (a) the last $80 \mathrm{C}$-terminal residues of $B$. pseudomallei SctQ (upper) against the equivalent region of $R$. solanacearum HrcQ (lower); (b) B. pseudomallei predicted protein product of ORF1 (upper) against $R$. solanacearum HpaP (lower); (c) B. pseudomallei predicted protein product of ORF2 (upper) against $R$. solanacearum HrpV (lower). Identical residues are indicated by a vertical line. Two dots represent a greater similarity than one dot. 
isms, the $\mathrm{G}+\mathrm{C}$ mol\% content of the type III secretion system genes has been reported to be lower than the mean genomic value, suggesting that the ancestral type III secretion system genes may have evolved in a low $\mathrm{G}+\mathrm{C}$ mol\% host [6]. Recently, a type III secretion system was identified in chlamydia [28], a potential candidate for such a role. In the B. pseudomallei gene cluster, the $\mathrm{G}+\mathrm{C} \mathrm{mol} \%$ content is lower in those areas with the greatest degree of conservation (Fig. 1).

Although it is believed that type III secretion systems are acquired in intact genetic blocks, considerable degrees of variation in conservation of proteins have been observed [6]. There are a number of examples, in type III secretion systems, where genes are conserved in relative location whilst exhibiting low sequence homologies [6]. Whilst SctQ, SctR and SctS homologues are found in all type III secretion systems, HpaP and $\mathrm{HprV}$ homologues are restricted to a group including $R$. solanacearum, B. pseudomal$l e i$, and in the case of HpaP, $X$. campestris. Furthermore, the protein homologies exhibited by these proteins (not thought to be integral membraneassociated components of the type III secretion structure) are far lower than for SctQ (C-terminal region), SctR or SctS, despite their positional conservation. This variation is consistent with the idea that certain proteins have undergone greater evolutionary change than others, with possible roles specific to individual secreted proteins or adaptation to different hosts, and with the higher $\mathrm{G}+\mathrm{C} \mathrm{mol} \%$ content, more typical of Burkholderia, observed in the less conserved regions.

In $R$. solanacearum, a gap between $\mathrm{HpaP}$ and HrcQ (HrpQ) coding regions defines the beginning of transcription unit 4 , although the exact location of a promoter is not known [13]. In B. pseudomallei, the presence of a putative ribosome binding-site (AGGA) has been used to identify the probable start codon. Although no promoter sequence has been identified, the gap between the first and second ORFs in $B$. pseudomallei (Fig. 1) may be indicative of a similar gene organisation and regulation between the two organisms.

The role of a $B$. pseudomallei type III secretion system has yet to be elucidated, but the presence of such systems has been implicated in the pathogenicity of several other gram-negative bacterial pathogens $[4$, $6,10]$. One of the major goals in further characterising a putative $B$. pseudomallei type III secretion system is to identify potential secreted virulence factors. The type III secretion pathways of plant pathogenic bacteria, found to form two distinct groups, have been characterised in E. amylovora, P. syringae, $X$. campestris and R. solanacearum. The Erwinia Hrp genes are closely related to the $P$. syringae Hrp genes (group I) whilst Ralstonia and Xanthomonas genes form a second group (group II) [12]. Group I and group II proteins are as distantly related to each other as they are to Yersinia type III secretion genes. The genes encoding the secreted proteins (harpins) are located adjacent to the secretion system genes in Erwinia ( $h r p N)$ and Ralstonia (popA), but within the secretion system gene cluster in $P$. syringae ( $h r p Z$ ). This proximity to the PI gene clusters, although not always the case, suggests that sequencing approaches could be used to identify a gene encoding a secreted product.

Michiels and Cornelis [29] demonstrated that successful secretion of the Yop proteins by the Yop type III secretion system of Yersinia was dependent on the Nterminal regions. Yet there was little homology between the $\mathrm{N}$-terminal regions of the different secreted proteins. The authors suggested that the secretion signal may be conformational. More recently Anderson and Schneewind [30] have suggested that the signal may be encoded in the mRNA rather than the protein. This indicates that the gene encoding a secreted protein would not be readily identified by the use of genes encoding other secreted proteins as probes. However, Yahr et al. [31] reported some Nterminal homology between the different secreted proteins in $P$. aeruginosa. In addition, the authors were able to identify several proteins secreted by a type III secretion system by comparing extracellular protein production in wild-type and type III secretion system mutants, an approach which may also prove fruitful in $B$. pseudomallei now that the genes of a putative secretion system have been identified.

B. pseudomallei is a facultative intracellular pathogen [32]. Effector molecules secreted by type III secretion systems have been implicated in stimulation of entry into normal non-phagocytic cells by Shigella spp. [33] and $S$. Typhimurium [34], although the principal function of type III secretion is thought to be protein translocation into host cells [10]. Type III secretion systems have been widely identified as playing an essential role in interactions between bacterial pathogens and their hosts. Therefore, the presence of a type III secretion system gene cluster in $B$. pseudomalle $i$ is indicative of some role in the pathogenicity of this organism. The sequence data reported in this study will allow the production of specifically targeted mutants and demonstration of the importance of the gene cluster in pathogenicity by the use of animal models. Hardt and Galán [35] reported a type IIIsecreted salmonella protein with homology to an avirulence determinant of the plant pathogen $X$. campestris. The identification of $B$. pseudomallei secreted proteins will make it possible to determine any similar relationships between $B$. pseudomalle $i$ and $R$. solanacearum proteins.

It has been suggested that specific components of type III secretion systems could be targeted in order to inhibit the delivery of virulence factors to plant 
pathogens [11]. Given the widespread emergence of studies indicating the importance of type III secretion systems in human bacterial pathogens, this intriguing possibility should not be discounted as a future therapeutic goal in man.

This work was supported by an award to C.W. from The Wellcome Trust (grant no. 044249/PMG/VW). We thank Dr Matthieu Arlat and Patrick Barberis (Laboratoire de Biologie Moléculaire des Relations Plantes-Microorganismes, INRA-CNRS, BP27, 31326 Castanet Tolosan Cedex, France) for kindly providing strains. We also thank Angela Rosin for DNA sequencing. This work benefited from the use of the SEQNET facility, Daresbury.

\section{References}

1. Leelarasmee A, Bovornkitti S. Melioidosis: review and update. Rev Infect Dis 1989; 11: 413-425.

2. Ashdown LR, Koehler JM. Production of hemolysin and other extracellular enzymes by clinical isolates of Pseudomonas pseudomallei. J Clin Microbiol 1990; 28: 2331-2334.

3. Sexton MM, Jones AL, Chaowagul W, Woods DE. Purification and characterization of a protease from Pseudomonas pseudomallei. Can J Microbiol 1994; 40: 903-910.

4. Mecsas JJ, Strauss EJ. Molecular mechanisms of bacterial virulence: type III secretion and pathogenicity islands. Emerg Infect Dis 1996; 2: 271-288.

5. Hacker J, Blum-Oehler G, Mühldorfer I, Tschäpe H. Pathogenicity islands of virulent bacteria: structure, function and impact on microbial evolution. Mol Microbiol 1997; 23 : 1089-1097.

6. Hueck CJ. Type III protein secretion systems in bacterial pathogens of animals and plants. Microbiol Mol Biol Rev 1998; 62: 379-433.

7. Salmond GPC, Reeves PJ. Membrane traffic wardens and protein secretion in Gram-negative bacteria. Trends Biochem Sci 1993; 18: 7-12.

8. Pugsley AP. The complete general secretory pathway in gramnegative bacteria. Microbiol Rev 1993; 57: 50-108.

9. Fath MJ, Kolter R. ABC transporters: bacterial exporters. Microbiol Rev 1993; 57: 997-1017.

10. Galán JE, Bliska JB. Cross-talk between bacterial pathogens and their host cells. Annu Rev Cell Develop Biol 1996; 12: 221-255.

11. He SY. Hrp-controlled interkingdom protein transport: learning from flagellar assembly? Trends Microbiol 1997; 5: 489-495.

12. Alfano JR, Collmer A. The type III (Hrp) secretion pathway of plant pathogenic bacteria: trafficking harpins, avr proteins, and death. J Bacteriol 1997; 179: 5655-5662.

13. Van Gijsegem F, Gough C, Zischek C et al. The hrp gene locus of Pseudomonas solanacearum, which controls the production of a type III secretion system, encodes eight proteins related to components of the bacterial flagellar biogenesis complex. Mol Microbiol 1995; 15: 1095-1114.

14. Winstanley C, Hales BA, Corkill JE, Gallagher MJ, Hart CA. Flagellin gene variation between clinical and environmental isolates of Burkholderia pseudomallei contrasts with the invariance among clinical isolates. J Med Microbiol 1998 47: $689-694$

15. Boucher CA, Van Gijsegem F, Barberis PA, Arlat M, Zischek C. Pseudomonas solanacearum genes controlling both pathogenicity on tomato and hypersensitivity on tobacco are clustered. J Bacteriol 1987; 169: 5626-5632.
16. Winstanley C, Carter JP, Seasman M, Morgan JAW, Pickup RW, Saunders JR. A comparison of the survival of stable and unstable chromosomally-located $x y l E$ marker cassettes as an indicator of cell division within populations of Pseudomonas putida released into lake water and soil. Microb Releases 1993; 2: 97-107.

17. Pearson WR, Lipman DJ. Improved tools for biological sequence comparison. Proc Natl Acad Sci USA 1988; 85 2444-2448.

18. Kyte J, Doolittle RF. A simple method for displaying the hydropathic character of a protein. J Mol Biol 1982; 157: 105-132.

19. Eisenberg D, Weiss RM, Terwilliger TC. The hydrophobic moment detects periodicity in protein hydrophobicity. Proc Natl Acad Sci USA 1984; 81: 140-144.

20. Gough CL, Genin S, Lopes V, Boucher CA. Homology between the HrpO protein of Pseudomonas solanacearum and bacterial proteins implicated in a signal peptide-independent secretion mechanism. Mol Gen Genet 1993; 239: 378-392.

21. Fields KA, Plano GV, Straley SC. A low-Ca2 ${ }^{+}$response (LCR) secretion (ysc) locus lies within the $\operatorname{lcr} B$ region of the LCR plasmid in Yersinia pestis. $J$ Bacteriol 1994; 176: 569-579.

22. Sasakawa C, Komatsu K, Tobe T, Suzuki T, Yoshikawa M Eight genes in region 5 that form an operon are essential for invasion of epithelial cells by Shigella flexneri 2a. J Bacteriol 1993; 175: 2334-2346.

23. Li J, Ochman H, Groisman EA et al. Relationship between evolutionary rate and cellular location among the Inv/Spa invasion proteins of Salmonella enterica. Proc Natl Acad Sci USA 1995; 92: 7252-7256.

24. Bonas U. Hrp genes of phytopathogenic bacteria. Curr Top Microbiol Immunol 1994; 192: 79-98.

25. Hales BA, Morgan JAW, Hart CA, Winstanley C. Variation in flagellin genes and proteins of Burkholderia cepacia. $J$ Bacteriol 1998; 180: 1110-1118.

26. Sajjan US, Sun L, Goldstein R, Forstner JF. Cable (Cbl) type Il pili of cystic fibrosis-associated Burkholderia (Pseudomonas) cepacia: nucleotide sequence of the cblA major subunit pilin gene and novel morphology of the assembled appendage fibers. J Bacteriol 1995; 177: 1030-1038.

27. Palleroni NJ. Family I. Pseudomonadaceae. In: Kreig NR, Holt JG (eds) Bergey's Manual of systematic bacteriology. Baltimore, MD, Williams \& Wilkins. 1984: 141-199.

28. Hsia R, Pannekoek Y, Ingerowski E, Bavoil PM. Type III secretion genes identify a putative virulence locus of Chlamydia. Mol Microbiol 1997; 25: 351-359.

29. Michiels T, Cornelis GR. Secretion of hybrid proteins by the Yersinia Yop export system. J Bacteriol 1991; 173: $1677-1685$

30. Anderson DM, Schneewind O. A mRNA signal for the type III secretion of Yop proteins by Yersinia enterocolitica. Science 1997; 278: $1140-1143$.

31. Yahr TL, Mende-Mueller LM, Friese MB, Frank DW. Identification of type III secreted products of the Pseudomonas aeruginosa exoenzyme S regulon. J Bacteriol 1997; 179: 7165-7168

32. Jones $\mathrm{AL}$, Beveridge $\mathrm{TJ}$, Woods $\mathrm{DE}$. Intracellular survival of Burkholderia pseudomallei. Infect Immun 1996; 64: 782-790.

33. Ménard R, Dehio C, Sansonetti PJ. Bacterial entry into epithelial cells: the paradigm of Shigella. Trends Microbiol 1996; 4: 220-226.

34. Galán JE. Molecular genetic basis of Salmonella entry into host cells. Mol Microbiol 1996; 20: 263-271.

35. Hardt WD, Galán JE. A secreted Salmonella protein with homology to an avirulence determinant of plant pathogenic bacteria. Proc Natl Acad Sci USA 1997; 94: 9887-9892. 